Çukurova Üniversitesi Mühendislik Mimarlık Fakültesi Dergisi, 33(2), ss. 83-92, Haziran 2018

Çukurova University Journal of the Faculty of Engineering and Architecture, 33(2), pp. 83-92, June 2018

\title{
Üniversite Kampüs Binaları için Enerji Etüdü: Örnek Çalışma
}
Selmin Ener RÜŞEN ${ }^{* 1}$, Mehmet Ali TOPÇU², Gamze KARANFIL CELEP ${ }^{1}$, Seyit Alperen ÇELTEK ${ }^{1}$, Aydın RÜŞEN ${ }^{2}$

\author{
${ }^{1}$ Karamanoğlu Mehmetbey Üniversitesi, Mühendislik Fakültesi, Enerji Sistemleri Mühendisliği \\ Bölümü, Akademik Enerji Çalışma Grubu (AKEN), Karaman \\ ${ }^{2}$ Karamanoğlu Mehmetbey Üniversitesi, Mühendislik Fakültesi, Metalurji ve Malzeme \\ Mühendisliği Bölümü, Akademik Enerji Çalışma Grubu (AKEN), Karaman
}

Geliş tarihi: 06.03.2018 Kabul tarihi: 29.06.2018

\section{$\ddot{\mathbf{O z}}$}

Günümüzde artan enerji maliyetleri ve çevresel endişeler binalarda enerjinin verimli kullanımını zorunlu kılmıştır. Yapı sektöründe enerji tasarrufu sağlamak amacıyla yüksek enerji tüketimi olan üniversiteler odak haline gelmiştir. Üniversitelerde enerjinin verimli kullanılması ile hem enerji maliyetlerinin üniversite bütçesi üzerindeki yükü hafifletilebilecek, hem de sürdürülebilir üniversite kriterleri için önemli bir adım atılabilecektir. Bu yüzden, bu çalışmada Karamanoğlu Mehmetbey Üniversitesi'nin (KMÜ) enerji açısından mevcut durumu ortaya çıkarılmış ve enerji verimlilik potansiyeli incelenmiştir. Öncelikle, KMÜ yerleşkesine ait binalarda kullanılan enerji tüketim değerleri belirlenmiş, enerji tüketim noktalarında uygun cihazlar (termal kamera, baca gazı analizörü, ultrasonik debimetre vb.) kullanılarak düzenli ölçümler alınmıştır ve bu noktalarda verimlilik artırıcı projeler önerilmiştir. Elde edilen sonuçlara göre, üniversitemizin 2016 y1lı enerji tüketim değerinin 1422 ton eşdeğer petrol (TEP) değerine ulaştığ1 ve \%18'e kadar enerji tasarruf potansiyelinin olduğu tespit edilmiştir.

Anahtar Kelimeler: Enerji verimliliği, Bina, enerji ve ölçüm, Karaman

\section{Energy Audit for Campus Buildings of University: A Case Study}

\begin{abstract}
Today, increasing costs and environmental concerns have forced to use energy efficiently in the buildings. Universities with high energy consumption have become the focus in order to save energy in the building sector. The efficient use of energy in universities will alleviate the economic burden of energy costs on the university budget as well as an important step for sustainable university criteria. Therefore, in this study, Karamanoğlu Mehmetbey University's (KMU) energy situation was revealed and energy efficiency potential was examined. Firstly, the energy consumption values used in the buildings belonging to KMU settlement were determined, regular measurements were taken using appropriate equipment (thermal camera, flue gas analyzer, ultrasonic flow meter etc.) at energy consumption points and productivity improvement projects were proposed for these points. According to the measurement results, it is determined that the energy consumption value of the university reached to 1422 tons equivalent petrol (TEP) annually and energy saving potential could be obtained up to $18 \%$.
\end{abstract}

Keywords: Energy efficiency, Building, energy and measurements, Karaman

*Sorumlu yazar (Corresponding author): Selmin ENER RÜŞEN, selmin.enerrusen@gmal.com 


\section{GíRiș}

Ülkemizde, son yıllarda artan nüfus ve sanayi faaliyetleri ile birlikte yükselen enerji talebimiz ve mevcut enerji kaynaklarımızın sınırlı oluşu ülkemizde enerjinin verimli kullanılmasına ilişkin çalışmaları zorunlu hale getirmiştir. Enerjinin doğru ve verimli kullanılması ile sağlanacak enerji tasarrufu daha ucuza elde edilebilen bir enerji kaynağıdır ve ülke ekonomisi üzerindeki enerjiden kaynaklanan maliyetlerin düşürülmesinin yanı sıra sera gazlarının neden olduğu iklim değişikliklerinin azaltılmasına ve enerji arz güvenirliliğinin artırılmasına katkıda bulunacaktır [1]. Konut, hastane, alışveriş merkezi ve eğitim veren binalarda tüketilen enerji dünyada olduğu gibi ülkemizde de toplam enerji tüketimindeki payı oldukça yüksektir [2]. Dolayısıyla yapılardaki enerji tüketiminin azaltılması, binalarda kullanılan enerjinin yenilenebilir enerji kaynaklarından sağlanması, yapıların dış cephelerindeki yalıtımın standartlarla belirlenmiş iklim şartlarına göre dizayn edilmesi ile 1sıtma için harcanan enerjinin azaltılması, gün 1şı̆̆ından faydalanmanın en uygun düzeye taşınması önem arz etmektedir. Bununla birlikte, binalarda verimli aydınlatma ve elektrikli cihazların kullanılması ve doğal havalandırmanın bina tasarımında kurgulanması gibi uygulamalar günümüzde yapılarda enerjinin verimli bir şekilde kullanılması için sıklıkla incelenen konulardır [3]. Eğitim sektöründe önemli rol oynayan üniversite yerleşke binaları, geleceklerini şekillendirmek isteyen gençlere ve akademik çalışma yapmak isteyen insanlara firsat sunan, idari ve teknik personeli barındıran ve günün her saatinde faaliyet gösteren kurumlardır. Üniversite yerleşkelerinde bulunan binalarının çok ve çeşitli olması, enerji ve su tüketiminin yüksek, ortaya çıkan kimyasal ve kimyasal olmayan atıkların miktarlarının fazla ve satın alınan malzemelerinin çeşitli sayıda olmasına sebep olmaktadır. Ancak kullanılabilir kaynakların sınırlı, atık depolama ve atıkların imha edilmesi konusunda ilgili personelin eğitimlerinin dar kapsamlı olması ve yenilebilir enerji kaynakları kullanımı için teşviklerin az olması sonucu insana hizmet veren birçok binada olduğu gibi eğitim kurumlarında da "çevreci" kavramını gündeme getirmiştir [4]. Ayrıca, ilk defa 1972 yılında Birleşmiş Milletlerin İsveç/Stockholm'de gerçekleştirilen İnsan ve Çevre Konferansında ortaya çıkan "Sürdürülebilir Kalkınma" kavramı ile birlikte sürdürülebilir üniversite; kendi faaliyetlerini gerçekleştirirken çevresel, sosyal ve ekonomik açıdan ortaya çıkan olumsuz etkileri en aza indirmek için çalışan ve topluma sürdürülebilir bir yaşam biçimi konusunda öncülük eden yükseköğrenim kurumu olarak tanımlanmıştır. Sürdürülebilir üniversite; yeşil üniversite veya yeşil yerleşke olarak da isimlendirilmektedir $[5,6]$.

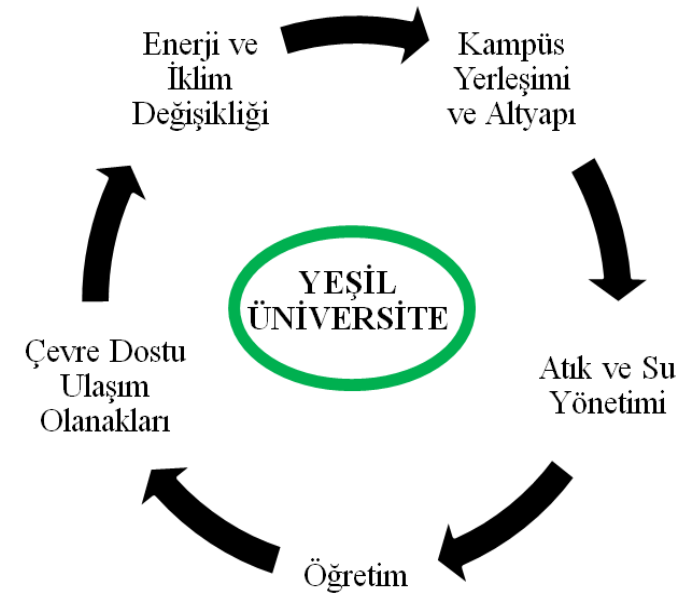

Şekil 1. Yeşil üniversite değerlendirmesinde yer alan 6 ana gösterge

Enerji ve iklim değişikliği göstergesi yeşil üniversite derecelendirmesi $\% 21$ ile en yüksek ağırlığa sahip göstergedir ve üniversitelerin enerji verimliliği ve enerji kaynakları konusundaki çalışmalarını değerlendirmektedir [7]. Bu yüzden eğitim-öğretim faaliyetlerinin gerçekleştirildiği binalarda "çevreci" kavramı ile tükenebilir kaynak kullanımına alternatif üretmek, harcanan enerjinin, suyun ve malzemenin daha verimli bir şekilde kullanılmasını teşvik etmek, her türlü israfın önüne geçmek ve çevre dostu bina tasarımlarını gerçekleştirmek önemli hale gelmiştir. Son dönemde yapılar tarafindan tüketilen enerjinin kontrol edilmesi ve azaltılmasına yönelik artan ilgi, yeni tasarımlarda iklim bilinçli yapı tasarımını gündeme getirdiği kadar, mevcut yapılar için de iyileştirme, verimlileştirme çalışmalarının gerekliliğini ortaya koymaktadır [8,9]. Yapılan kapsamlı araştırmalar ve literatür taraması sonucu, "yeşil" kavramının, çevre dostu stratejiler 
belirleyen yerleşkeler için dünya çapında uzun y1llardır kullanıldığı anlaşılmaktadır. Ancak ülkemizde yeşil üniversite kavramının yeni olduğu ve yeşil üniversite yerleşke sınıfına giren üniversite sayısının çok az olduğu görülmektedir.

$\mathrm{Bu}$ sebeple, bu çalı̧̧mada bir üniversite yerleşkesinde olası enerji tüketim noktalarının ön plana çıkarılması ve bunlara yönelik verimlilik arttricı uygulamalar ile elde edilebilecek enerji tasarrufu miktarına dikkat çekilmesi amaçlanmıştır. Bu kapsamda, KMÜ Bilimsel Araştırmalar Projeleri Koordinatörlüğü tarafindan desteklenen "KMÜ Kampüs Binaları için Enerji Kullanımı Etüt Çalışmaları" başlığı ile yürütülen projenin sonuçları bu çalışmada paylaşılmaktadır. KMÜ yerleşkesine ait binaların 2014-2016 yıllarındaki enerji tüketim değerleri dikkate alınarak yerleșkedeki binalarının enerji tüketimi açısından durumu incelenmiş, temel tüketim noktalarında ölçümler alınarak üniversitemizin enerji verimlilik potansiyeli ortaya çıkarılmıştır. Ayrıca, bunların geri dönüş hesapları ile verimlilik arttırıcı projeler konusunda fizibilite çalışmaları yapılmıştır.

\section{MATERYAL VE METOT}

KMÜ yerleşkesinde bulunan binalar bu enerji etüt çalı̧̧ması için deneysel çalışma bölgesi olarak seçilmiştir. Çalışma kapsamında kullanılan enerji tüketim bilgileri kurum kayıtlarından alınmıştır. Yerleşke binalarının ve enerji tüketim noktalarının tasarruf potansiyellerinin incelenmesi için çeşitli ölçüm cihazları kullanılmış ve tüm ölçümler 22.08.2016-20.05.2017 tarihleri arasında düzenli olarak alınmıştır. Bu ölçümler için KMÜ Enerji Verimliliği Ar-Ge laboratuvarında bulunan Testo Marka baca gazı analizörü (Testo 350), termal görüntüleme kamerası (Testo 875-2i), sıvı debisi ölçme cihazı (Transport PT970), çok fonksiyonlu ve kızılötesi sıcaklık ölçüm cihazı (Testo 435), elektrik enerji analizörü (Mertel 2883) ve U değeri ölçüm cihazları (Testo 635-2) kullanılmıştır. Çalışma sırasında alınan bazı ölçümler Şekil 2'de gösterilmiştir.
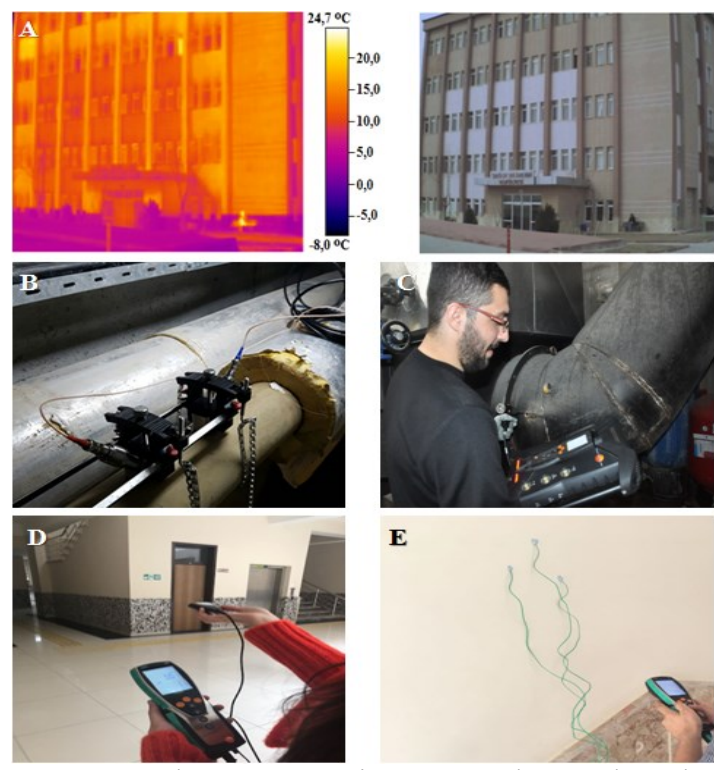

$\mathbf{E}$

Şekil 2. Çalışma süresince yapılan ölçümler, a) Termal kamera görüntüsü, b) debimetre ölçümü, c) bacagazı analizi, d) aydınlatma şiddeti ölçümü, e) U değeri ölçümü

Is1 merkezinde bulunan buhar kazanı yüzey sıcaklığı termal kamera ve kızıl ötesi sicaklık ölçüm cihazı ile, baca gazı özellikleri ise baca gazı analizörü ile belirlenmiştir. Kazan sisteminde kullanılan doğal gazın içeriği ve temel özellikleri bölgede faaliyet gösteren doğalgaz dağıtım şirketinden [10] temin edilmiştir. Doğalgaz ile çalıştırılan bir kazan sistemindeki olası kayıplar (kuru baca gazından kaynaklı 1sı kaybı, nemden kaynaklı 1sı kaybı, baca gazı içinde yanmamış karbonmonoksit kaynaklı 1s1 kayb1, kazan yüzeyinden olan $1 \mathrm{~s} 1 \mathrm{kayb}$ vb.) $[11,12]$ dikkate alınarak kazan verimlilik hesaplamaları ve baca gazı atık 1sı hesaplamaları önceki çalışmalarda kullanılan eşitlikler yardımıyla yapılmıştır $[13,14]$. Kampüs içerisindeki binaların iç ve dış sicaklıkları termal kamera ve kızıl ötesi sıcaklık ölçüm cihazı ile, bina duvarlarının 1sı yalıtım durumları ise termal kamera ve $U$ değeri ölçüm cihazları ile belirlenmiştir. Dış duvar yalıtım hesaplamaları, TS-825 standardı [15] ve önceki çalışmalarda [16,17] kullanılan eşitlikler dikkate alınarak yapılmıştır. Tüm bu çalışmalarda kullanılan hesaplamalarda $5 \mathrm{~cm}$ Taşyünü ile yalıtım yapılması durumu ortaya konulmuştur. 
Kampüs içerisinde kullanılan elektrik sisteminde aktif güç/reaktif güç oranları, kaçak akım ve kompanzasyon değerlerini belirlemek üzere elektrik enerji analizörü ve panolarda termal kamera kullanılmıştır. Aydınlık seviyesi ölçümleri Lüksmetre ile gerçekleştirilmiştir. Aydınlatma hesaplarında bir fabrika içerisinde yer alan aydınlatma ekipmanları üzerinde yapılan çalışmalardaki temel eşitlikler kullanılmıştır [18]. Yapılan ölçümler ve değerlendirmeler sonrası üniversitemizin enerji haritası ortaya çıkarılmıştır. Ayrıca, üniversitemiz yerleşkesinde bulunan binalarda kullanılan enerji tüketim değerleri, olası 1sı kaçakları ve verimsiz kullanılan enerji miktarı belirlenerek, bu alanlarda verimlilik artırıcı projeler önerilmiştir. Çalışma kapsamında $\mathrm{CO}_{2}$ salınımı ile ilgili hesaplamalar yapılarak verimlilik arttırıc1 projeler sonrası $\mathrm{CO}_{2}$ salınımındaki azalmalar tespit edilmiştir.

\section{BULGULAR VE TARTIŞMA}

KMÜ yerleşkesinde farklı amaçlar için kullanılan 21 adet bina bulunmaktadır. Bu binalarda enerji kaynağı olarak elektrik ve doğalgaz kullanılmakta ve yerleşke içinde herhangi bir enerji üretim tesisi bulunmamaktadır. Yerleşke binalarının kullandığı elektrik şehir şebekesinden sağlanırken, doğal gaz 1s1 merkezi'nde kullanılarak binaların isınma ihtiyacı karşılanmaktadır. Yapılan değerlendirmeler sonunda, yerleşke binalarında kullanılan enerji 2014-2016 yılları arasında giderek artmış ve 3 yıl için toplamda 3517 TEP enerji kullanılmıştır. KMÜ'nde sırasıyla 2014, 2015, 2016 yıllarına ait enerjinin tüketim dağılımı ve toplam enerjinin maliyet dağılımı oranları sırasıyla Şekil 3 ve Şekil 4'te verilmiştir.

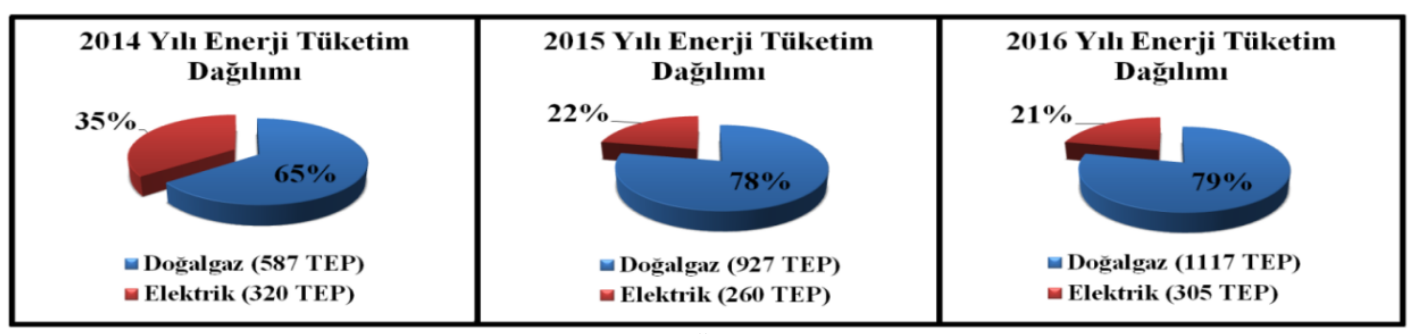

Şekil 3. 2014-2016 yıllarında KMÜ'ne ait tüketilen enerjinin dağılımı

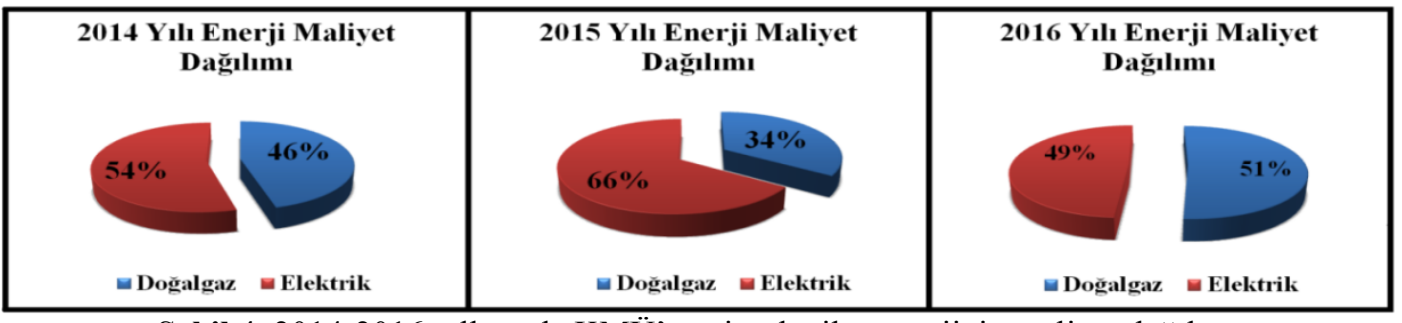

Şekil 4. 2014-2016 yıllarında KMÜ’ne ait tüketilen enerjinin maliyet dağılımı

Grafiklerden anlaşılacağı üzere, yıllar geçtikçe tüketilen enerjinin dağılımında kullanılan doğal gazın payı artmıştır. Doğal gaz artışına paralel olarak elektrik tüketiminde de bir artış gözlenmiştir. Ancak, yıllar geçtikçe tüketilen toplam enerjinin TEP cinsinden artışının ana bileşenini doğalgaz tüketimi oluşturmaktadır. Doğal gaz kullanımdaki bu artış, yerleșkemizin içerisinde yapımı devam eden binaların yıldan yıla tamamlanması ve kullanıma açılması sonucu 1sıtılan kapalı alanların artmasından ve doğal gaz kullanımının yaygınlaşmasından kaynaklanmaktadır. Doğal gaz kullanımındaki bu artış, enerjinin maliyet dağılımında doğalgazdan kaynaklı maliyetlere de yansımıştır. Üniversite yerleşkemizin $\mathrm{CO}_{2}$ salınımı ile ilgili çalışmalar 2014, 2015, 2016 yıllarına ait enerji tüketim değerleri dikkate alınarak hesaplanmıştır. 
Karamanoğlu Mehmetbey Üniversitesi'nde geçmiş üç yıla ait $\mathrm{CO}_{2}$ salınım değerleri Çizelge 1 'de gösterilmiştir.

Üniversite yerleşkemizde 2014 yılında ortaya çıkan $\mathrm{CO}_{2}$ salınımı 3118,9 ton/ay iken, 2016 yılında $\% 41$ oranında artarak 4410,7 ton/ay miktarına çıkmıştır. Üniversite yerleşkesinde 2014-2016 yılları arasında $\mathrm{CO}_{2}$ salınımındaki bu artışın temelini doğal gaz kullanımındaki artış oluşturmaktadır. Yukarda grafiklerle Karamanoğlu Mehmetbey Üniversitesi'nin son üç yıllık enerji tüketimleri değerleri ve maliyetleri belirlenerek enerji kullanım haritası ortaya çıkarılmıştır. Enerjinin kullanım yerleri, gerçekleşen kayıplar ve tasarruf miktarları belirlenmiştir.

Çizelge 1. 2014-2016 yılları arasında üniversite yerleşkesinde ortaya çıkan $\mathrm{CO}_{2}$ salınım değerleri

\begin{tabular}{|c|c|c|c|}
\hline \multirow{2}{*}{ Y1llar } & \multicolumn{3}{|c|}{$\mathrm{CO}_{2}$ Salınımı (Ton/ay) } \\
\cline { 2 - 4 } & Doğalgaz & Elektrik & Toplam \\
\hline 2014 & 1515,75 & 1603,05 & 3118,9 \\
\hline 2015 & 2393,76 & 1300,00 & 3693,8 \\
\hline 2016 & 2884,36 & 1526,29 & 4410,7 \\
\hline
\end{tabular}

Çalışma kapsamında, üniversite 1S1 merkezinde 01.11.2016 - 01.04.2018 tarihleri arasında haftalık düzenli baca gazı ölçümleri yapılarak yanma havasının optimizasyonu, baca gazı ile birlikte atılan atık 1sının geri kazanımı ve 1sı merkezinde kurulabilecek kojenerasyon sistemi ile elde edilecek tasarruf miktarları belirlenmiştir. Bununla birlikte, yerleşke içerisinde bulunan tüm binaların 1S1 yalıtım durumları incelenmiştir. Ayrıca, bu etüt çalışmasında elektrik enerjisi verimliliğinde önemli bir ölçüt olan reaktif güç oranları, kaçak akım ve kompanzasyon gerektiren uygulamalar da incelenmiştir. Üniversitemizin tüm aydınlatma sistemleri incelenmiş, mevcut armatür tipleri, güçleri ve sayıları tespit edilerek aydınlatma alanında verimlilik arttırıcı projeler belirlenmiştir. Yapılan değerlendirmeler ve hesaplamalar sonucu üniversitemiz yerleşkesinde yapılabilecek verimlilik arttırıcı projeler, enerji ve maliyet açısından elde edilebilecek tasarruflar ve $\mathrm{CO}_{2}$ salınımındaki azalmalar Çizelge 2'de dört başlık altında özetlenmiştir.

Çizelge 2. Yerleşke içerisinde uygulanabilecek verimlilik arttırıcı projeler

\begin{tabular}{|c|c|c|c|c|c|c|c|c|}
\hline \multirow{2}{*}{ Önlemler } & \multirow{2}{*}{$\begin{array}{c}\text { Enerji } \\
\text { Türü }\end{array}$} & \multicolumn{4}{|c|}{ Tasarruf Miktarı } & \multirow{2}{*}{$\begin{array}{c}\begin{array}{c}\text { Yatırım } \\
\text { Maliyeti }\end{array} \\
\text { TL }\end{array}$} & \multirow{2}{*}{$\begin{array}{c}\text { Geri Ödeme } \\
\text { Süresi } \\
\text { Yıl }\end{array}$} & \multirow{2}{*}{$\begin{array}{c}\text { Azaltılan } \mathrm{CO}_{2} \\
\text { Salınımı } \\
\text { (Ton/yıl) }\end{array}$} \\
\hline & & Miktar & Birim & TEP/YIl & TL/YII & & & \\
\hline $\begin{array}{l}\text { Yanma Havasının } \\
\text { Optimizasyonu }\end{array}$ & Doğalgaz & 48,42 & $\mathrm{~m}^{3} / \mathrm{h}$ & 57 & 79.488 & - & - & 190,1 \\
\hline $\begin{array}{l}\text { Bacagazından } \\
\text { Atılan Atık Isının } \\
\text { Ekonomizer } \\
\text { Uygulamas1 } \\
\end{array}$ & Doğalgaz & 16,49 & $\mathrm{~m}^{3} / \mathrm{h}$ & 119 & 78.810 & 52800 & 0,67 & 396,9 \\
\hline $\begin{array}{l}\text { Bina Kabuklarının } \\
\text { Yalıtılmas1 }\end{array}$ & Doğalgaz & 11,91 & $\mathrm{~m}^{3} / \mathrm{h}$ & 49,9 & 68.250 & 154700 & 2,26 & 166,4 \\
\hline $\begin{array}{l}\text { Aydınlatma } \\
\text { Sistemlerinin } \\
\text { Iyileștirilmesi }\end{array}$ & Elektrik & 495.194 & $\mathrm{kWh} / \mathrm{Y}_{11}$ & 42,60 & 357.164 & 252890 & 1,16 & 247,6 \\
\hline & & & Toplam & 268,5 & & & Toplam & 1001 \\
\hline
\end{tabular}

\subsection{Yanma Havasının Optimizasyonu}

Üniversite yerleşkesinde bulunan 1sı merkezinde toplam kurulu gücü $15000 \mathrm{KW}$ olan 3 adet kızgın su kazanı mevcuttur. Bu kazanlardan sürekli aktif olarak kullanılan 1 nolu kazana ait haftalık düzenli ölçümler sonucunda elde edilen bacagazı çıkış sıcaklıkları, bacagazı analiz sonuçları ve kazanın bulunduğu ortam sıcaklıklarına ait veriler aylık ortalama değerler olarak Çizelge 3 'te sunulmuştur. İyi bir yanma için gerekli olan fazla hava oranı yakıt tipine ve yakıcı sisteme göre değişiklik göstermekle birlikte doğalgaz ile yakılan kazanlarda \%5-12 aralığında olması yeterli 
görülmüştür [19]. Bu sebeple, haftalık rutin olarak alınan ölçümler sırasında bacadan atılan gazın bileşimi kontrol edilmiş ve bileşenlerinden $\mathrm{O}_{2}$ ile $\mathrm{CO}$ miktarlarının durumuna göre brülör ayarına müdahale edilmiştir. Alınan ölçümlerde kasım ve şubat aylarında olmak üzere iki kez bacagazı bileşenlerinden $\quad \mathrm{O}_{2} \quad(22$ Kasım- \%13,81; 8 Şubat- \%5,47) ve CO (Kasım- 2520 ppm; Şubat-1086 ppm) miktarlarının çok fazla olduğu görülmüştür. Yapılan müdahaleler sonucunda fazla hava oranının kasım ayında \%49'dan \%26'ya, Şubat ayında yapılan ayarlama ile\%36'dan \%10 değerine kadar düşürülebilmiştir (Şekil 5).

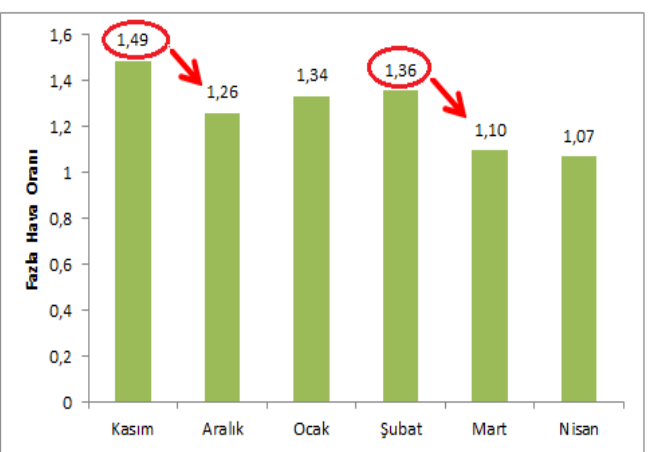

Şekil 5. Brülör ayarı ile fazla hava oranının düşürülmesi

Çizelge 3. Yapılan bacagazı ölçümlerinin aylık ortalama verileri

\begin{tabular}{|c|c|c|c|c|c|}
\hline Aylar & Bacagazı Sıcaklığı $\left({ }^{\circ} \mathbf{C}\right)$ & $\mathbf{O}_{2}$ miktarı (\%) & CO miktarı (ppm) & CO $_{2}$ miktarı (\%) & Ortam Sıcaklığı ( $\left.{ }^{\circ} \mathbf{C}\right)$ \\
\hline Kasım & 171,10 & 8,04 & 78,80 & 7,40 & 26,92 \\
\hline Aralık & 164,87 & 4,35 & 85,67 & 9,51 & 20,63 \\
\hline Ocak & 215,70 & 5,27 & 817,33 & 8,93 & 23,07 \\
\hline Şubat & 294,70 & 5,53 & 1086,33 & 8,75 & 20,17 \\
\hline Mart & 232,97 & 1,85 & 614,33 & 10,89 & 30,13 \\
\hline Nisan & 228,60 & 1,41 & 1361,50 & 11,09 & 32,75 \\
\hline
\end{tabular}

$\mathrm{Bu}$ ölçümler sonucu kazan sistemine ait brülördeki hava/yakıt oranının iyi ayarlanmamış olduğunda; i) sisteme verilen hava miktarı çok fazla ise gereksiz yere havayı 1sıtıp bacagazı olarak dışarı atılması, ii) sisteme verilen hava yeterli değilse tam yanma sağlanamadan yakıtın bir kısmının atık gaz olarak bacadan dişarı atılması durumları ile karşıllaşılabileceği anlaşılmaktadır. $\mathrm{Bu}$ sebeple, alınan bu ölçümlerin sonucunda kazanın brülör sistemine müdahale edilerek brülöre giren hava miktarı kısılmış ve kısa bir süre sonra bacagazındaki $\mathrm{O}_{2}$ ve $\mathrm{CO}$ değerlerinin normale döndüğü gözlemlenmiştir. Brülör sistemindeki hava/yakıt oranının ayarlanması maliyetsiz bir işlem olması nedeniyle sürekli olarak kontrol edilmesi durumunda önemli oranda enerji tasarrufu sağlanabilmektedir [20].

\subsection{Bacagazı Atık Isısının Değerlendirilmesi}

Çalışma kapsamında Üniversite yerleşkesinde bulunan 1s1 merkezindeki 1 nolu kazana ait bacagazı ölçümleri düzenli olarak alınmış ve bacadan atılan atık 1sının değerlendirilmesi üzerine bir planlama yapılmıştır. Genel olarak bacagazı atık ısılarının geri kazanılması için su-hava (ekonomizer) veya hava - hava (reküperatör) tipi 1S1 değiştiriciler yaygın olarak kullanılmaktadır [21-24]. Kazan sistemini terk eden bacagazı sıcaklığ 1 genellikle $150-250{ }^{\circ} \mathrm{C}$ arasında değiştiği için 1s1 enerjisinin önemli bir kısmı (\%10-30) bu yolla kaybedilebilmektedir. Bu enerji kaybının en aza indirgenmesi için, yapılan bu çalışmada, bacagazı atık 1sınının yoğuşmalı ekonomizer uygulamasiyla önemli oranda geri kazanılabileceğinin mümkün olduğu belirlenmiştir. Kazan sisteminde kullanılan doğal gazın özellikleri [10] kullanılarak ve bir kazan sistemindeki olası kayıplar [11,12] dikkate alınarak yapılan hesaplamalar ile bacagazı atı 1sisının geri kazanılması sonucu yıllık 119 TEP karşılığında 78.810,82 TL tasarruf edilebileceği ortaya çıkarılmıştır.

\subsection{Bina Kabuklarının Isı Yalıtımı}

Çizelge 2'de yer aldığı üzere, bu çalışma kapsamında yapılan enerji verimliliği önerilerinden bir diğeri ise bina kabuklarının 1s1 yalıtım durumlarının incelenmesidir. $\mathrm{Bu}$ amaçla, yerleşkemizde bulunan tüm binaların 1sı yalıtım durumları termal kamera ve $U$ değeri ölçüm 
cihazları ile incelenmiș, yalıtımı yetersiz görülen binaların bina kabukları uygun yalıtım malzemesi (5 cm kalınlıkta Taşyünü) ile kaplanarak önemli ölçüde bir enerji tasarrufu sağlanabileceği ve üniversitemizin kayda değer miktarda ekonomik kazanç sağlayacağı tespit edilmiştir. TS-825 standard 1 temel alınarak yapılan incelemede, Üniversite yerleşkesinde özellikle 10 yıldan daha eski binaların yalıtımlarının yeterli olmadığ (Şekil 2-a), yeni binaların yalıtımlarının ise çok iyi durumda olduğu tespit edilmiştir. Ayrıca, 2016 yılında yerleşke içerisine yapılan yüzme havuzunun bina yalıtımının iyi olmasına rağmen pencerelerin 1Sı yalıtımı açısından yetersiz olduğu tespit edilmiştir. Yerleşke içerisindeki tüm binaların termal kamera ile yapılan incelemeleri neticesinde Kampüs içerisindeki eski binalara ait toplam $4.826 \mathrm{~m}^{2}$ dış yüzeyin yalıtılması önerilmiş ve bu izolasyonun toplam yalitım maliyeti 154.700 TL olarak belirlenmiştir. Binaların yalıtılması ve isı yalıtımı açısından daha uygun pencerelerin kullanımı ile yapılacak verimlilik arttırıcı proje ile saatte $11,91 \mathrm{~m}^{3}$ doğal gazın tasarruf edilebileceği hesaplanmıştır.

\subsection{Elektrik ve Aydınlatma Sistemi}

Üniversitemiz yerleşkesinde kullanılan elektrik sisteminden alınan ölçümlerde belirtilen tarihler arasında şebekeden çekilen görünür güç, aktif güç ve reaktif güç değerleri kayıt altına alınmıştır ve endüktif-kapasitif oranlar ile birlikte Çizelge 4 'te sunulmuştur.

Çizelge 4. Ağustos 2016 - Nisan 2017 arası enerji tüketim değerleri ve endüktif-kapasitif oranlar

\begin{tabular}{|c|c|c|c|c|c|}
\hline Tarih & Aktif Tüketim (KW) & Endüktif Tüketim (kVAr·h) & Kapasitif Tüketim (kVAr·h) & $\begin{array}{c}\text { Endüktif } \\
\text { Oran } \\
(\%)\end{array}$ & $\begin{array}{c}\text { Kapasitif } \\
\text { Oran (\%) }\end{array}$ \\
\hline Ağustos 2016 & 220572,450 & 8344,350 & 4781,700 & 3,8 & 2,2 \\
\hline Eylül 2016 & 220241,700 & 7285,950 & 7456,050 & 3,3 & 3,4 \\
\hline Ekim 2016 & 272424,600 & 13466,250 & 11132,100 & 4,9 & 4,1 \\
\hline Kasım 2016 & 319117,050 & 28255,500 & 6539,400 & 8,9 & 2,0 \\
\hline Aralık 2016 & 378756,000 & 44292,150 & 3487,050 & 11,7 & 0,9 \\
\hline Ocak 2017 & 323076,600 & 33273,450 & 2031,750 & 10,3 & 0,6 \\
\hline Şubat 2017 & 291031,650 & 25893,000 & 3591,000 & 8,9 & 1,2 \\
\hline Mart 2017 & 315941,850 & 38187,450 & 3638,250 & 12,1 & 1,2 \\
\hline Nisan 2017 & 198242,100 & 20119,050 & 4243,050 & 10,1 & 2,1 \\
\hline
\end{tabular}

Ölçüm sonuçlarına göre, üniversitemizde hattan çekilen güçler (aktif ve reaktif) son derece hassas bir şekilde kompanze edildiği anlaşılmaktadır. 09/01/2007 tarih ve 26398 sayll Resmi Gazete'de yayınlanan Elektrik Piyasası Müşteri Hizmetleri Yönetmeliği'ne göre bağlantı gücü 50 kVA'nın üstünde olan kullanıcılar çektikleri aktif enerji miktarının \%33'ünü aşan şekilde endüktif-reaktif enerji tüketmeleri veya tükettikleri aktif enerji miktarının \%20'sini aşan şekilde sisteme kapasitif-reaktif enerji vermeleri halinde, reaktif enerji tüketim bedeli ödemekle yükümlüdür. Çizelge 4'den de açıkça görüldüğü üzere üniversite güç tüketimimiz hiç bir zaman belirtilen sınırlar dışına çıkmamış ve cezai yaptırıma düşmemiştir. Ayrica, termal kamera ile yapılan incelemelerde elektrik panolarında herhangi bir 1sınma veya kaçak tespit edilmemiştir. Üniversitemiz elektrik tüketiminde yıldan yıla bir artış söz konusu olsa da kişi başı tüketim miktarında fazla bir değişiklik meydana gelmemiştir.

Kişi başı elektrik tüketimindeki değişiklikler dönemsel olarak farklılıklar göstermekte olup 2017 yılı için kişi başı yıllık elektrik tüketim değeri ortalama 24,17 KW olarak hesaplanmıștır. Özellikle kış aylarında elektrik tüketiminde bir artış meydana gelmekte olup $30,38 \mathrm{KW}$ ile maksimum noktaya ulaşmaktadır. Hesaplamalara göre, yaz aylarında ise kişi başına elektrik tüketimi 17,99 KW değerine kadar düşmektedir. Yapılan detaylı incelemeler sonucu üniversitemizde tüketilen elektrik enerjisinin büyük bir kısmının kapalı ve açık mahalleri aydınlatmak için kullanıldığı tespit edilmiştir. $\mathrm{Bu}$ çalıșmada, aydınlatmada sistemlerinin iyileştirilmesi için önerilen verimlilik artırıcı proje, aydınlatmanın kalitesini düşürmeden ve iyi bir aydınlatmanın 
gereklilikleri yerine getirilerek yapılmıştır. Kampüs içerisinde farklı güçlerde $(10-400 \mathrm{~W})$ ve türlerde (Akkor filamanll, Floresan ve Metal Halide vb.) 14.454 adet lambanın olduğu tespit edilmiştir. Kaliteli ve tasarruflu bir aydınlatma için mevcut aydınlatma sistemlerinin yerine son zamanlarda siklıkla daha verimli olan LED lambaların tercih edildiği bilinmektedir [24,25]. Üniversitemiz yerleşkesinde bulunan floreans ve akkor filamanlı lambaların yıllık tüketilen elektrik enerjisi ile aynı ş̧ık konforunu sağlayacak şekilde bunların yerine LED kullanılması durumunda tüketilecek enerji farkı dikkate alınarak yapılan hesaplamalara göre; verimli aydınlatma sistemleri tercih edildiğinde bir yılda 495.194 KWh'lık enerji tasarruf edilebileceği tespit edilmiştir. Yapılan yatırımın ise basit geri ödeme yöntemiyle yapılan hesaba göre kendini 1,16 y1lda amorti edeceği belirlenmiştir.

\subsection{Kojenerasyon Sisteminin Belirlenmesi}

Üniversitemizde şehir şebekesinden temin edilen doğalgaz ve elektrik enerjileri ısınma ihtiyacının karşılanması, mahallerin aydınlatılması ve elektrikli cihazların çalıştırılması için kullanılmaktadır. Yıllar geçtikçe artan 1sınma ve elektrik enerjisi ihtiyacı ile birlikte yükselen enerji fiyatları üniversite ekonomisi üzerinde ağır bir yük oluşturacağı aşikardır. 2014-2016 yılları arası yıllık kampüs içerisinde tüketilen elektrik ve doğal miktarları göz önünde bulundurulduğunda, üniversitemizin elektrik ve 1sınma ihtiyacının karşılanması için son yıllarda endüstriyel işletmelerde sıklıkla kullanılmaya başlanan kojenerasyon sisteminin kurulması, yukarıda önerilen (Çizelge 2) enerji verimliliği uygulamaları dışında yeni bir verimlilik arttırıcı proje olarak sunulmuştur. Üniversitemizde aylık ortalama tüketilen elektrik enerjisinin miktarı göz önünde bulundurularak yapilan hesaplamalarda 2 adet 600 KWh'lık gaz motoru ile bir kojenerasyon tesisi kurulması önerilmiştir. Hem 1sının hem de elektriğin yoğun olarak birlikte tüketildiği Kasım-Mart ayları arasında kojenerasyon sisteminin toplam verimliliği yaklaşık olarak \%84 olarak hesaplanmıştır [26-29]. Elektrik ve ısınma ihtiyacının karşılanması amacıyla kojenerasyon sisteminin kurulması basit geri ödeme yöntemine göre yaklaşık 3,5 yılda kendini amorti edeceği ve sonraki y1llarda ise üniversite ekonomisine katk1 sağlayacağ 1 tespit edilmiştir. $\mathrm{Bu}$ süre enerji verimliliği kapsamında değerlendirildiğinde 5 yılın altında olup ortalama seviyede verimlilik arttırıcı proje olarak değerlendirilmektedir ve uygulanabilir niteliktedir. Ancak, kojenerasyon sistemlerinin yatırım maliyetinin yüksek olması (2 adet 600 KWh'lik kojenerasyon tesis maliyeti; 5.120.000 TL) bu destek miktarının kamu kurumları tarafından tedarik edilmesini oldukça güç kılmaktadır.

\section{SONUÇ}

Üniversitelerin bulunduğu bölgeye sağladığ1 yararlar ile birlikte sahip oldukları farklı birimler nedeniyle, çevreye dolaylı olarak olumsuz etkileri de bulunmaktadır. Sürdürülebilir veya yeşil üniversite kriterini sağlamak için en önemli unsur olan enerji ve iklim değişikliği konusunda ülkemiz üniversitelerinde yapılan çalışmalar kısıtlıdır. Bu konu kapsamında, çalışmamızda, Karamanoğlu Mehmetbey Üniversitesi yerleşkesinde enerjinin verimli kullanılabileceği noktalar tespit edilerek verimlilik arttırıcı projeler önerilmiştir. Yapılan detaylı incelemeler ve hesaplamalar ardından; yerleşkede yanma havasının optimizasyonu, baca gazından atılan atık 1sının geri kazanımı, bina kabukların yalıtılması, 1s1 merkezine kojenerasyon sisteminin kurulması ve aydınlatma sistemlerinin verimlileştirilmesi konularında projeler önerilmiştir. Bu projeler sonunda y1llık 268,5 TEP birim enerjinin tasarruf edilebileceği ve üniversite ekonomisini üzerindeki enerji maliyetinin azaltılabileceği tespit edilmiştir. Ayrıca gerçekleştirilecek olan projeler sonucu yılda yaklaşık olarak 1001 ton $\mathrm{CO}_{2}$ atmosferden uzaklaştırılarak çevre ve iklim değişikliği konusunda olumlu adımlar atılabilecektir.

\section{TEŞEKKÜR}

$\mathrm{Bu}$ çalışmanın yapılmasını "Karamanoğlu Mehmetbey Üniversitesi Kampüs Binaları için Enerji Kullanımı Etüt Çalışmaları" başlıklı ve 24-M-16 nolu proje numarasi ile destekleyen Karamanoğlu Mehmetbey Üniversitesi Bilimsel 
Araştırmalar Projeleri Koordinatörlüğü'ne teşekkür ederiz.

\section{KAYNAKLAR}

1. Aydın, M., 2016. Enerji Verimliliğinin Sürdürülebilir Kalkınmadaki Rolü: Türkiye Örneği. Yönetim Bilimleri Dergisi, 14(28), 409-411.

2. Yılmaz, Z., 2006. Akıllı Binalar ve Yenilenebilir Enerji. Tesisat Mühendisliği Dergisi, 91, 7-15.

3. Çakmanus, İ., Kaş, İ., Künar, A., Gülbeden, A., 2010. Yüksek Performanslı Sürdürülebilir Binalara İlișkin Bir Değerlendirme. Yeşil Bina Dergisi, 3(4), 461-462.

4. Terekli, G., Özkan, O., Bayın, G., 2013. Çevre Dostu Hastaneler: Hastaneden Yeşil Hastaneye. Ankara Sağlık Hizmetleri Dergisi, 12 (2), 37-54.

5. Velazquez, L., Munguia, N., Platt, A., Taddei, J., 2006. Sustainable University: What can be The Matter?. Journal of Cleaner Production, 14(9), 810-819.

6. Günerhan, S.A., Günerhan, H., 2016. Türkiye İçin Sürdürülebilir Üniversite Modeli. Engineer $\&$ the Machinery Magazine, 57(682), 54-62.

7. http://greenmetric.ui.ac.id/ son erişim tarihi: 12.11.2017

8. Bektaş, B., Aksoy, U.T., 2005. Soğuk İklimlerdeki Binalarda Pencere Sistemlerinin Enerji Performans1. Firat Üniv. Fen ve Müh. Bil. Dergisi, 17(3), 499-508.

9. Aykal, F.D., Gümüş, B., Özbudak Akça, Y.B., 2009. Sürdürülebilirlik Kapsamında Yenilenebilir ve Etkin Enerji Kullanımının Yapılarda Uygulanmasi. V. Yenilenebilir Enerji Kaynakları Sempozyumu (YEKSEM), Diyarbakır.

10. www.enerya.com.tr

11. K1lıç, F.Ç., 2017. Endüstriyel Kazanlarda Enerji Verimliliği ve Emisyon Azalımı Frrsatlar1. Gazi Üniversitesi Fen Bilimleri Dergisi Part C: Tasarım ve Teknoloji, 5(2), 147-158.

12. Barma, M.C., Saidur, R., Rahman, S.M.A., Allouhi, A., Akash, B.A., Sait, S.M.A., 2017. Review on Boilers Energy use, Energy
Savings, and Emissions Reductions. Renewable and Sustainable Energy Reviews, 79, 970-983.

13. Celep, G.K., Rüşen, S.E., 2016. Application of Economizer for Waste Heat Recovery from Exhaust Flue Gas in Steam Boiler: a Case Study in a Biscuit Factory. $4^{\text {th }}$ International Symposium on Innovative Technologies in Engineering and Science (ISITES), Antalya.

14. Celep, G.K., Rüşen, S.E., 2017. The Waste Heat Recovery in the Furnace: a Case Study in a Biscuit Factory. International Conference on Material Science and Technology (IMSTEC), Nevşehir.

15. TS 825, Binalarda Isı Yalıtım Kuralları, Türk Standartları, TSE, 1998, Ankara.

16. Kaya, M., Fırat, İ., Çomaklı, Ö., 2016. Erzincan İlindeki Binalarda Isı Yalıtımın Enerji Tasarrufuna Etkisinin Ekonomik Analizi. Is1 Bilimi ve Tekniği Dergisi, 36(1), 47-55.

17. Kürekçi, A., Bardakçı, A. T., Çubuk, H., Emanet Ö., 2012. Türkiye'nin Tüm İlleri için Optimum Yalıtım Kalınlığının Belirlenmesi. Tesisat Mühendisliği, 131, 5-21.

18. Rüşen, S.E., Karanfil G., Çeltek S.A., 2016. Enhancement of Lighting Efficiency in a Factory. International Ege Energy Symposium and Exhibition (IEESE8), Afyonkarahisar.

19. Considine, D.M., 1997. Energy Technology Handbook, 1, Mcgraw-Hill, A.B.D.

20. Rüşen, A., Topçu, M.A., Rüşen, S.E., 2017. Improvement in Energy Efficiency of Boiler By Periodic Measurements. International Conference on Material Science and Technology (IMSTEC), Nevşehir.

21. Noie, S.H., 2006. Investigation of Thermal Performance of an Air-to-air Thermosyphon Heat Exchanger using $\varepsilon$-NTU Method. Applied Thermal Engineering, 26(5-6), 559-567.

22. Wei, M., Zhao, X., Fu, L., Zhang, S., 2017. Performance Study and Application of New Coal-fired Boiler Flue Gas Heat Recovery System. Applied Energy, 188, 121-129.

23. Wang, C., He, B., Yan, L., Pei, X., Chen, S., 2014. Thermodynamic Analysis of a LowPressure Economizer Based Waste Heat Recovery System for a Coal-fired Power Plant. Energy, 65, 80-90. 
24. Singh, D., Basu, C., Meinhardt-Wollweber, M., Roth, B., 2015. LEDs for Energy Efficient Greenhouse Lighting. Renewable and Sustainable Energy Reviews, 49, 139-147.

25. Jones, B.A., 2018. Measuring Externalities of Energy Efficiency Investments using Subjective Well-Being Data: The Case of LED Streetlights. Resource and Energy Economics, 52, 18-32.

26. Mura, P.G., Innamorati, R., 2015. Design of a New System of High-power Efficiency Conditioning Cogeneration Energy for a Building of the University of Cagliari with fossil fuel plants. Energy Procedia, 78, 1111-1116.

27. Kaya, A., Duymaz, M.M., İmal, M., 2016. Bir Kağıt Fabrikasındaki Kojenerasyon Tesisinin Enerji ve Ekserji Analizi. Kahramanmaraş Sütçü İmam University Journal of Engineering Sciences, 19(2), 58-69.

28. Ener Rusen, S., Erkayıran, Y.C., 2017. The Energy Efficiency Potential of Lighting Systems in the University Campus. Ecology 2017 International Symposium, Kayseri.

29. Ener Rusen, S., Yoldas, M.G., 2017. Energy Efficiency and Environment in Karaman with the Cogeneration Systems. Ecology 2017 International Symposium, Kayseri. 